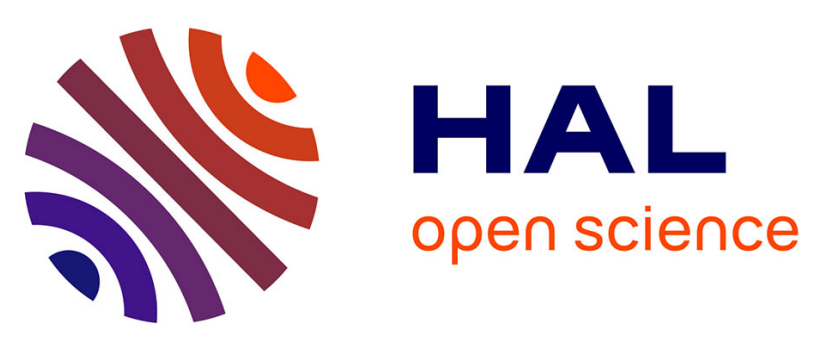

\title{
Absolute total and partial cross sections for ionization of nucleobases by proton impact in the Bragg peak velocity range
}

J. Tabet, S. Eden, S. Feil, H. Abdoul-Carime, B. Farizon, M. Farizon, S. Ouaskit, T.D. Märk

\section{To cite this version:}

J. Tabet, S. Eden, S. Feil, H. Abdoul-Carime, B. Farizon, et al.. Absolute total and partial cross sections for ionization of nucleobases by proton impact in the Bragg peak velocity range. Physical Review A : Atomic, molecular, and optical physics [1990-2015], 2010, 82, pp.022703. 10.1103/PhysRevA.82.022703 . in2p3-00408267

\section{HAL Id: in2p3-00408267 https://hal.in2p3.fr/in2p3-00408267}

Submitted on 30 Jul 2009

HAL is a multi-disciplinary open access archive for the deposit and dissemination of scientific research documents, whether they are published or not. The documents may come from teaching and research institutions in France or abroad, or from public or private research centers.
L'archive ouverte pluridisciplinaire HAL, est destinée au dépôt et à la diffusion de documents scientifiques de niveau recherche, publiés ou non, émanant des établissements d'enseignement et de recherche français ou étrangers, des laboratoires publics ou privés. 


\title{
Absolute total and partial cross sections for ionization of nucleobases by proton impact in the Bragg peak velocity range
}

\author{
J. Tabet, S. Eden ${ }^{1}$, S. Feil, H. Abdoul-Carime, B. Farizon, M. Farizon, S. Ouaskit ${ }^{2}$, T.D. \\ Märk $^{3}$
}

Université de Lyon, F-69003, Lyon, France; Université Lyon 1, Villeurbanne; CNRS/IN2P3, UMR5822, Institut de Physique Nucléaire de Lyon; F-69622, Villeurbanne.

\begin{abstract}
We present experimental results for $80 \mathrm{keV}$ proton impact ionization of nucleobases (adenine, cytosine, thymine and uracil) based on an event by event analysis of the different ions produced combined with an absolute target density determination. We are able to disentangle in detail the various proton ionization channels from mass analyzed product ion signals in coincidence with the charge-analyzed projectile. Thus, for the first time, cross sections and fragmentation patterns are compared for direct ionization (with no charge transfer between the target molecule and the projectile) and for single electron capture (with projectile neutralization) in proton-nucleobase collisions. In addition we are able to determine a complete set of cross sections for the ionization of uracil by $20-150 \mathrm{keV}$ protons
\end{abstract}

Further to their fundamental importance in collision physics[1], molecular ionization and dissociation processes are of great interest in diverse areas of science ranging from plasma physics to radiation damage in biological tissues [2]. Today it is recognized that radiation damage in biomolecules, notably the formation of DNA strand breaks, is not only the result of a single interaction of the primary ionization projectile with the molecules involved, but also due to the simultaneous and consecutive action of the primary and the secondary species [3]. A detailed knowledge of ionization and dissociation processes involved including the various cross sections is a must for a full understanding of radiation damage on a microscopic level (see e.g. [4,5]).

This has led recently to an increased number of investigations on the interactions of the various primary and secondary species with DNA and its constituents. Gas and solid phase experiments have been carried out with isolated basic constituents of DNA (i.e., the nucleobases, phosphate, sugar, water subunits) involving target molecules and molecular compounds of increasing complexity. Many of these seminal studies have been devoted to the interaction of low energy electrons (e.g. see [6-13]). This work has led to major advances in understanding the role of the secondary low energy electrons in radiobiology with potential applications in radiotherapy [14].

\footnotetext{
${ }^{1}$ Dept. Physics and Astronomy, The Open University (OU), Walton hall, Milton Keynes, MK76AA, UK

${ }^{2}$ Université Hassan II-Mohammedia, Faculté des Sciences Ben M'Sik (LPMC), B.P.7955 Ben M'Sik, Casablanca, Morocco

${ }^{3}$ Institut für Ionenphysik und Angewandte Physik, Leopold Franzens Universitat, Technikerstrasse 25, A-6020

Innsbruck, Austria
} 
In contrast with electron-induced processes, investigations concerning proton (or heavier ions, for example see [15,16]) interactions with DNA and its constituents are rather scarce and a number of important details have not yet been investigated. This is particularly intriguing as the interaction of protons in the $\mathrm{keV}$ energy range with building blocks of DNA is of great biological relevance in view of the ever increasing number of proton therapy facilities using $\mathrm{MeV}$ proton irradiation [17]. When these protons enter the tissue they are decelerated reaching Bragg peak energies. These tumor treatments exploit the Bragg peak maximum and its volume selectivity based on the intricate interplay of the various primary and secondary interaction processes. Despite being such a promising tool for cancer treatment, most proton interaction studies reported so far have been restricted either to a specific type of cross section or have involved targets consisting of atoms or small (atmospheric) molecules. Although numerous total electron capture cross sections are available for proton interactions with gases [18-20], only recently have complete sets of ionization cross sections (including the total and the partial cross sections for direct ionization and electron capture) been reported for protons (or hydrogen) collisions with condensable molecular targets such as $\mathrm{H}_{2} \mathrm{O}$ [21-23]. In 2003 Coupier et al. [24] reported the first mass spectrum for the direct ionization of uracil with 20 to $150 \mathrm{keV}$ protons in comparison with electron impact ionization. Moretto-Capelle et al. [25] followed this up with an electron spectroscopy study obtaining double differential cross sections showing preferential emission of low energy electrons for $25-100 \mathrm{keV}$ proton impact on gas phase uracil. Alvarado et al. [26] recently used a new experimental approach to directly measure the amount of internal energy present in deoxyribose dications after $\mathrm{keV}$ proton collisions with gas phase molecules. Finally, Le Padellec et al. [27] reported mass spectra for $100 \mathrm{keV}$ proton impact ionization of gas phase cytosine, thymine and uracil.

In this letter we report on the application of a novel experimental set-up which allows us, on an event by event basis, to analyze in great detail proton impact ionization of nucleobases (adenine, cytosine, thymine and uracil) and to measure absolute partial and total single ionization cross sections as a function of the charge state of the projectile after the ionization event. Mass analyzed product ions were detected (providing fragmentation pattern data) in coincidence with the charge-analyzed projectile after the ionizing collision, i.e., $\mathrm{H}^{+}$ detection after direct ionization (DI), neutral $\mathrm{H}^{0}$ detection after single electron capture (EC), or $\mathrm{H}^{-}$detection after double electron capture $[28,29]$. The present study have become possible by the development of a temperature controlled Knudsen type molecular beam source with absolutely characterized target thickness. We are thus able to disentangle the various reaction channels in proton ionization of nucleobases and provide in addition absolute ionization and dissociation cross sections that are 'differential' in terms of the projectile state. This is the first time that absolute cross sections for proton ionization become available for targets which exist in the solid state (powder) under normal atmospheric conditions. In this letter we report on results involving positive product ion formation: direct ionization and single electron capture events.

The experimental apparatus is shown in Fig.1. It consists essentially of five parts (partially shown in Fig.1): Firstly, pure molecular hydrogen is ionized in a standard RFdischarge source [30]. Secondly, ions from the source are accelerated to $20-150 \mathrm{keV}$ with an energy resolution $\Delta \mathrm{E} / \mathrm{E}$ of 0.01 [30]. Thirdly, the primary magnetic sector field shown in Fig. 1 is used as a mass-selector to produce a pure beam of protons which is followed by a parallel plate deflector allowing to detect the primary ion beam. Fourthly, the proton beam intersects a perpendicular effusive jet of sublimated nucleobase molecules and the cross-beam interaction region is coupled to a time of flight mass spectrometer. The effusive neutral target beam jet is 
produced by sublimating nucleobase powder samples (purchased from Sigma-Aldrich, minimum purity 99\%) in a temperature controlled Knudsen type oven with a capillary exit of $1 \mathrm{~mm}$ diameter. The target thickness and distribution has been determined by combining mass measurements of the condensed nucleobases on a liquid nitrogen cooled aluminum plate mounted above the capillary exit with deposition patterns measured by optical interference analysis and calculated angular distribution profiles using Troitskii's vapor flow model [31]., the projectiles pass through a second (sector field type magnetic) mass selector combined with a multi-detector device using channeltrons that are located at different positions at the exit of the magnetic analyzer thus giving us information about the final charge state of the projectile (i.e., protons will be deflected and neutralized protons will be un-deflected by the magnet). We have checked single collision conditions by changing the densities of both beams. Finally, the nucleobase parent and fragment ions produced are extracted perpendicular to the direction of both, the projectile and the target beam, and then mass-to-charge analyzed in a time of flight analyzer in coincidence with the projectile signal at the multi-detector device. This allows us to record simultaneously the charged product ions produced in the target region and in coincidence for each single collision event the nature of the projectile (either $\mathrm{H}^{+}$or after electron capture neutral $\mathrm{H}$ ) after the ionizing collision.

As examples, Fig. 2 shows mass spectra for single ion production events in $80 \mathrm{keV}$ and $42 \mathrm{keV}$ protons collisions with gas-phase uracil. Each mass spectrum was constructed after the interaction of about $10^{7}-10^{8}$ protons with the target beam producing about $10^{4}$ product ions. Having applied our coincidence technique we can (in contrast to earlier studies with protons [24,27] and multiply charged ions [32]) distinguish between ions produced by direct ionization (DI) of uracil via $U+H^{+} \rightarrow$ ions $+H^{+}$and ions produced via electron capture (EC) via $U+H^{+} \rightarrow$ ions $+H$. Besides parent ion production strong fragmentation is observed for both EC and DI leading to the appearance of five groups of fragment ions with neighboring mass numbers. In both ionization processes, the total fragment ion abundance is clearly much larger than the respective parent ion abundance. Table 1 includes uracil fragmentation branching ratios (fragment ion production / total ion production) for EC and DI at selected energies in the range $27-150 \mathrm{keV}$. In general, this branching ratio is larger for EC than for DI. This can be rationalized by arguing that in case of the direct ionization mechanism less energy is transferred to the molecular system than for electron capture. Moreover, this fragmentation branching ratio is for both cases rather independent of the kinetic energy (Table1); only at energies below about $40 \mathrm{keV}$ does the fragmentation branching ratio increase strongly in the case of direct ionization (due to a strong decrease of the parent ion abundance), surpassing even that of the electron capture case. Finally, it should be mentioned that fragmentation patterns in case of direct ionization are rather similar to recent electron impact ionization mass spectra obtained in $[33,34]$.

Extension to other nucleobases (first line in Table1) shows that the branching ratio between the two ionization modes, EC and DI, as expressed for instance by the branching ratio $\mathrm{EC} / \mathrm{EC}+\mathrm{DI}$, is rather similar for these nucleobases, i.e. having values at $80 \mathrm{keV}$ proton energy of $27.1 \%, 27.6 \%, 26.6 \%$ and $25.4 \%$ for adenine, cytosine, thymine and uracil, respectively. These values are also close to the corresponding branching ratio measurements for gas-phase water yielding $27.8 \%$ and $25.7 \%$ in two different studies $[22,35]$. The rather similar ratios for the nucleobases and water suggest that molecular details (for instance the rather differing ionization energies which are important input parameters for the absolute cross sections) are not decisive for the relative probability of these two reactions. 
Besides these details on fragmentation and differences concerning the ionization mechanisms we are here also able to quantify the various reaction probabilities on an absolute scale for the first time. Figure 3 shows absolute cross sections in the energy range from 20 to $150 \mathrm{keV}$ for proton ionization of uracil giving values for the total ionization cross sections and cross sections for those reactions proceeding via electron capture and those via direct ionization. Whereas the total cross section decreases in line with the Born Bethe high energy limit, the individual EC and DI contributions show different behavior, i.e., the EC cross section is decreasing strongly with increasing proton energy, whereas the DI cross section only decreases at higher energy approaching the Born Bethe cross section. This leads to a situation that around the Bragg peak at $20 \mathrm{keV}$ the branching ratios are about $60 \%$ and $40 \%$ for EC and DI respectively, at around $35 \mathrm{keV}$ the two cross sections are equal and at the highest energy studied here, at $150 \mathrm{keV}$, the branching ratios approach $10 \%$ for EC and $90 \%$ for DI. This behavior appears to be universal as can be seen from Fig.4 where the uracil branching ratio for EC as a function of energy is compared to a number of other targets, including $\mathrm{He}[36]$ and some small molecules [22,35,36].

Finally, we are able here to compare experimental absolute cross section values for a series of nucleobases for the first time. Table 2 gives cross section values for $80 \mathrm{keV}$ protons collisions with adenine, cytosine, thymine and uracil. Surprisingly, while three of these nucleobases show rather similar values for the total, the EC and the DI cross sections, respectively, in contrast cytosine has in all three cases a cross section which is smaller by a factor of about 3. A deeper insight into the details of this may be obtained by comparing these results with absolute electron impact ionization cross sections calculated recently [37, 38] using the Deutsch-Märk (DM) and the Born and Bethe (BEB) methods, respectively. These semi-classical calculations take into account details of the electronic structure of the molecules under consideration and results obtained with DM and BEB agree in shape and magnitude. It is rather interesting to note that the maximum cross sections obtained in these calculations lie between 1.45 (uracil), 1.65 (cytosine) and 2.05 (adenine) $\times 10^{-15} \mathrm{~cm}^{2}$. This is quite different in the ordering and different in magnitude from the present proton results, i.e. the direct ionization cross sections for proton impact are about a factor of 4 (cytosine) to about 12 (uracil) larger than the electron ionization cross sections. This tendency is in accordance with our earlier observations in water when comparing electron cross sections with direct ionization cross sections taking into account the different projectile masses and comparing cross sections at the same velocities (see [22] and references therein) and has been attributed to target polarization effects. It was also argued that, at a fixed velocity, the lower kinetic energy of lighter projectiles reduces their cross sections relative to more massive counterparts as incident energy approaches the ionization potential of the target.

In conclusion, we have presented here the first results based on an event by event analysis for the proton impact ionization of gas phase nucleobases. This allows us to obtain a complete analysis in terms of the positive ions which are produced (and lost as in the case of reactions proceeding via electron capture by the proton). This experiment was possible after combining our high energy ion beam / multi-coincidence apparatus with a time of flight mass spectrometer operated in coincidence with the final projectile detection. This is the first time that a complete set of cross sections for the ionization of a target consisting of biologically relevant molecules (nucleobases) by proton impact has been obtained including the total and all partial cross sections, and, in addition, differentiating between the direct ionization and the electron capture mechanism. As this investigation yields a new wealth of information on proton impact ionization, we are confident that such measurements will provide an important impact and basis for future refinement of the theoretical treatment of these reactions and their influence in radiation biology. 
Acknowledgements.

The Institut de Physique Nucléaire de Lyon is part of IN2P3-CNRS, the French national research institute for nuclear and particle Physics. Financial support was provided by the French, Austrian, and Moroccan governments and the EU Commission (Brussels), through the Amadeus program, the PICS CNRS 2290 and the CNRS-CNRST convention $n^{\circ} 17689$. S. Eden acknowledges the FP6 Marie Curie Fellowship (IEF RADAM-BIOCLUS). 
References.

[1] E.W.McDaniel, J.B.A.Mitchell, M.E.Rudd, Atomic Collisions, Wiley, New York, 1993.

[2] See Molecules of Biological Interest in the Gas Phase, Experimental Tools and Quantum Chemistry, Euresco Conference, Centre de Physique des Houches, France, 2000.

[3] L.Sanche, Eur. Phys. J., D35 (2005) 367

[4] J. F.Ward, Radiat. Res. 104 (1985) S103

[5] P.Bernhardt, W.Friedland, P.Jacob and H.G. Paretzke, Int. J.Mass Spectrom., 223/224 (2003) 579

[6] B.Boudaiffa, P.Cloutier, D.Hunting, M.A.Huels and L.Sanche, Science, 287 (2000) 1658

[7] GHanel et al., Phys.Rev.Letters,

[8] S.Ptasinska et al., Angew. Chem. Int. Ed., 44 (2005)6941

[9] P.Burrow et al., J. Chem. Phys., 124 (2006) 124310

[10] S.Ptasinska et al., Angew. Chem. Int. Ed., 45 (2006) 1893

[11] S.Denifl et al., Angew. Chem. Int. Ed., 46 (2007) 5238

[12] S.Ptasinska et al., Angew. Chem. Int. Ed., 44 (2005) 1647

[13] S.Ptasinska et al., Phys. Rev. Letters, 95 (2005) 093201

[14] L.Sanche, Chem.Phys.Letters, 474 (2009) 115] S.Martin, R.Bredy, A.R.Allouche, J.Bernard, A.Salmoun, B.Li and L.Chen, Phys.Rev., A77 (2008) 0622513

[16] S.Bari, P.Sobocinski, J.Postma, F.Alvarado, R.Hoekstra, V.Bernigaud, B.Manil, J.Rangama, B.Huber and T.Schlathölter, J.Chem. Phys., 128 (2008) 074306

[17] S. Braccini, Nucl. Phys., B172 (2007) 8

[18] H.Tawara and A.Russek, Rev. Mod. Phys., 45 (1973) 178

[19] L.H.Toburen, IAEA-TECDOC, 799 (1995) 47

[20] H.Knudsen, U.Mikkelsen, K.Paludan, K.Kirsebom, S.P.Moller, E.Uggerhoj, J.Slevin, M.Charlton and E.Morenzoni, J.Phys., B28 (1995) 3569

[21] F. Gobet, B. Farizon, M. Farizon, M.J. Gaillard, M. Carré, M. Lezius, P. Scheier, T.D. Märk, Phys. Rev. Lett., 86 (2001) 3751

[22] F. Gobet, S. Eden, B. Coupier, J. Tabet, B. Farizon, M. Farizon, M.J. Gaillard, M. Carre, S. Ouaskit, T.D. Märk, P. Scheier, Phys. Rev., A 70 (2004) 062716

[23] F. Gobet, S. Eden, B. Coupier, J. Tabet, B. Farizon, M. Farizon, M.J. Gaillard, S. Ouaskit, M. Carre, T.D. Märk, Chem. Phys. Lett. 421 (2006) 68

[24] B.Coupier, B.Farizon, M.Farizon, M.J.Gaillard, F.Gobet, N.V.de Castro Faria, G.Jalbert, S.Ouaskit, M.Carre, B.Gstir, G.Hanel, S.Denifl, L.Feketeova, P.Scheier and T.D.Märk, Eur. Phys. J. D20 (2002) 459

[25] P.Moretto-Capelle and A.Le Padellec, Phys.Rev., A74 (2006) 062705

[26] F.Alvaro, J.Bernard, B.Li, R.Bredy, L.Chen, R.Hoekstra, S.Martin and T.Schlathölter, ChemPhysChem, 9 (2008) 1254

[27] A.Le Padellec, P.Moretto-Capelle, M.Richard-Viard, J.P.Champeaux and P.Carafelli, J.Phys. Conf.Series 101 (2008) 012007

[28] B.Farizon, M.Farizon, M.J.Gaillard, R.Genre, S.Louc, J.Martin, J.P.Buchet, M.Care, G.Senn, P.Scheier and T.D.Märk, Int.J.Mass Spectrom.Ion Proc., 164 (1997) 225

[29] B.Farizon, M.Farizon, M.J.Gaillard, F.Gobet, M.Carre, J.P.Buchet, P.Scheier and T.D.Märk, Phys. Rev. Lett., 81 (1998) 4108

[30] M.Carré, M.Druetta, M.L.Gaillard, H.H.Bukow, M.Horani, A.L.Roche and M.Velghe, Molec. Phys., 40 (1980) 1453

[31] V.S.Troitskii, Sov. Phys.JETP, 7 (1962) 353 
[32] T.Schlathölter, F.Alvarado and R.Hoekstra, Nucl. Instrum. Meth. Phys. Res., B233 (2005) 62

[33] S.Denifl, B.Sonnweber, G.Hanel, P.Scheier and TD.Märk, Int. J. Mass Spectrom., 238 (2004)47

[34] M.Imhoff, Z.Deng and M.Huels, Int. J. Mass Spectrom., 262 (2007) 154

[35] H.Luna, A.L.F.de Barros, J.A.Wyer, S.W.J.Scully, J.Lecointre, P.M.Y.Garcia, G.M.Sigaud, A.C.F. Santos, V.Senthil, M.B.Shah, C.J.Latimer and E.C. Montenegro, Phys.Rev., A75 (2007) 042711

[36] M.E.Rudd, R.D.DuBois, L.H.Toburen, C.A.Ratcliffe, and T.V.Goffe, Phys. Rev., A28 (1983) 3244

[37] P.Bernhardt and H.G.Paretzke, Int. J. Mass Spectrom., 223/224 (2003) 599

[38] P.Mozejko and L.Sanche, Radiat. Environ. Biophys., 42 (2003) 201 
Fig. 1: Schematic diagram of the experimental system

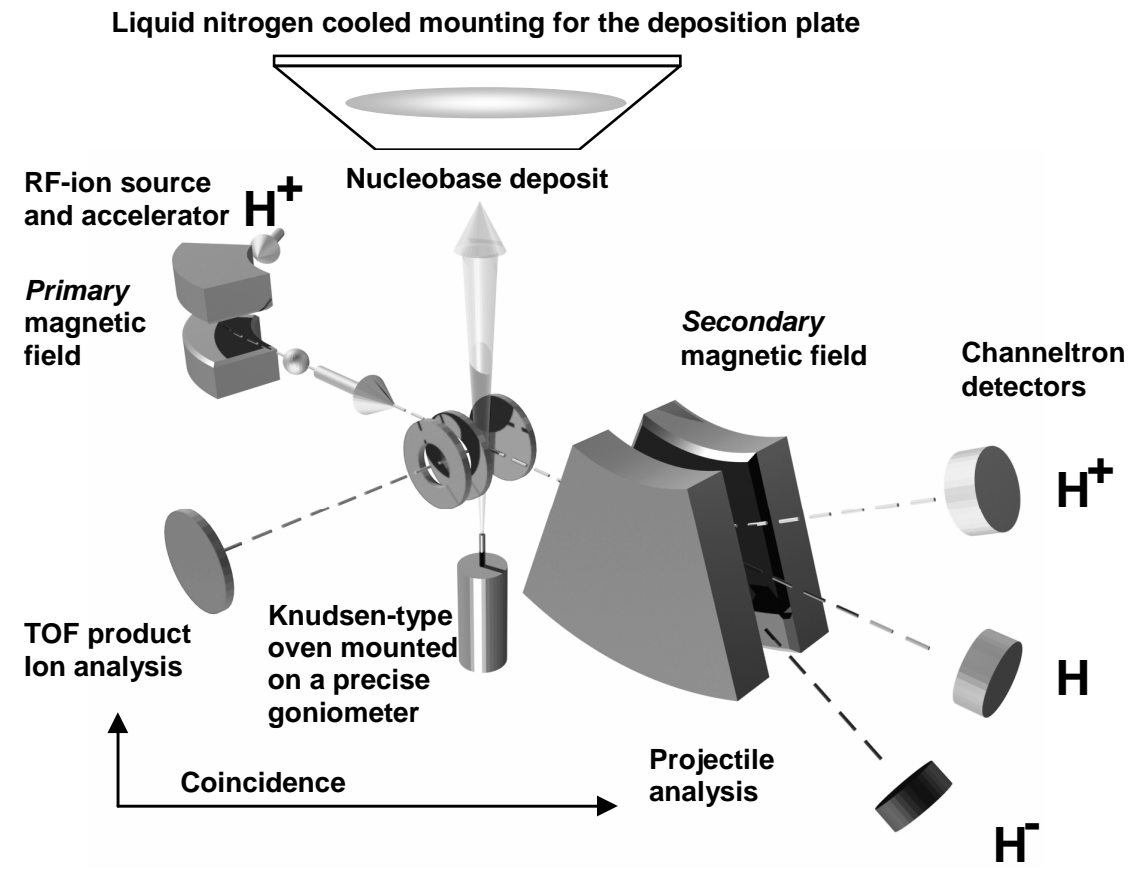


Fig 2: Mass spectra for direct ionization and electron capture in 80 and $42 \mathrm{keV}$ proton collisions with gas-phase uracil

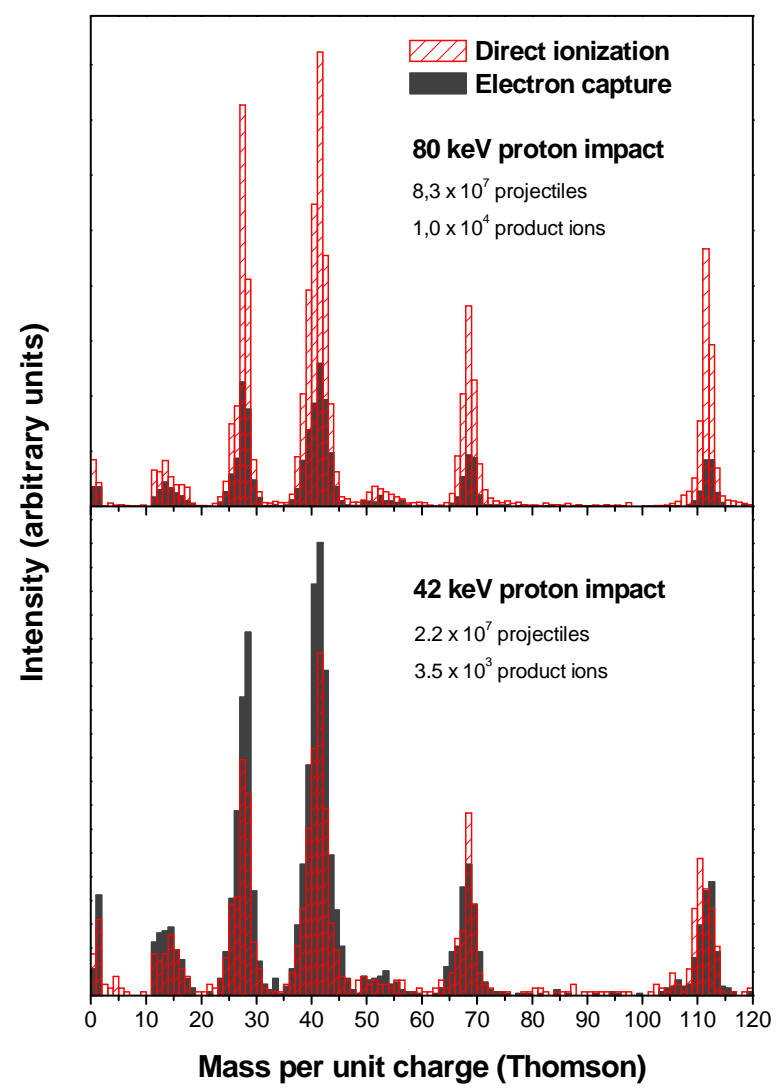


Fig 3 : Absolute cross sections in the energy range from 20 to $150 \mathrm{keV}$ for proton impact induced ionization of uracil including values for the total ionization cross sections and cross sections for those reactions proceeding via electron capture (EC) and those via direct ionization (DI). Open symbols designate measured absolute cross sections at $80 \mathrm{keV}$, filled triangles designate relative cross sections normalized to the absolute value at $80 \mathrm{keV}$, lines designate fits to the corresponding data points after normalization.

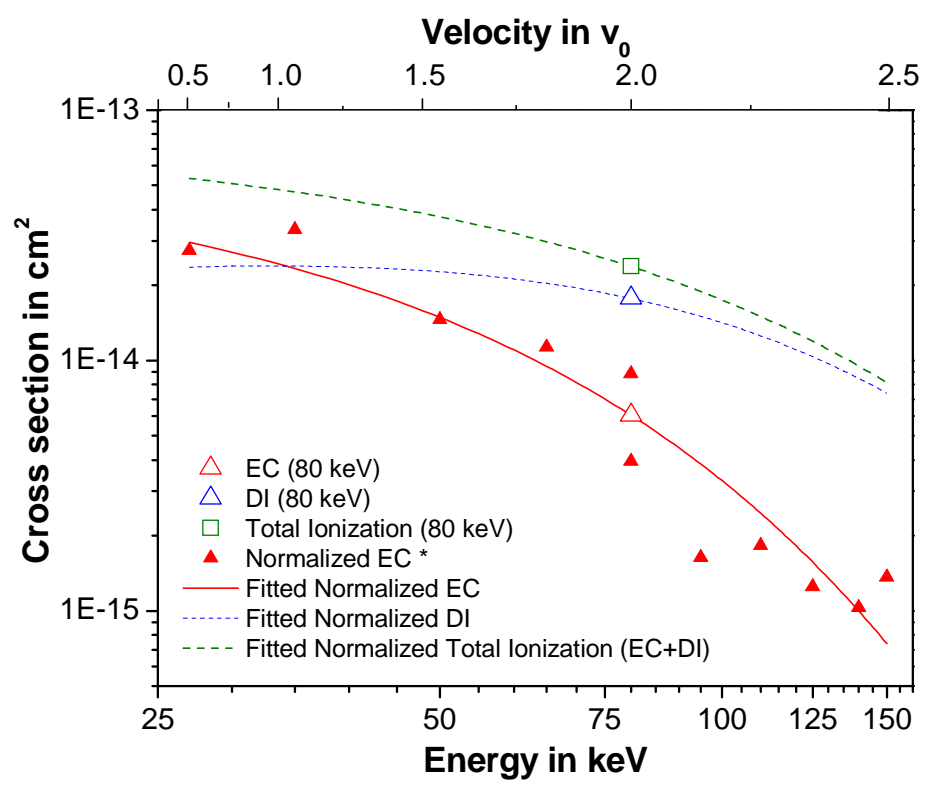


Fig. 4: Electron capture ionization of uracil as a percentage of total ionization (electron capture + direct ionization) following proton impact in the energy range $27-150 \mathrm{keV}$. The data are compared to previous results for $\mathrm{H}_{2} \mathrm{O}$ [22,35], and for $\mathrm{He}, \mathrm{CH}_{4}, \mathrm{CO}_{2}$, and $\mathrm{O}_{2}$ [36].

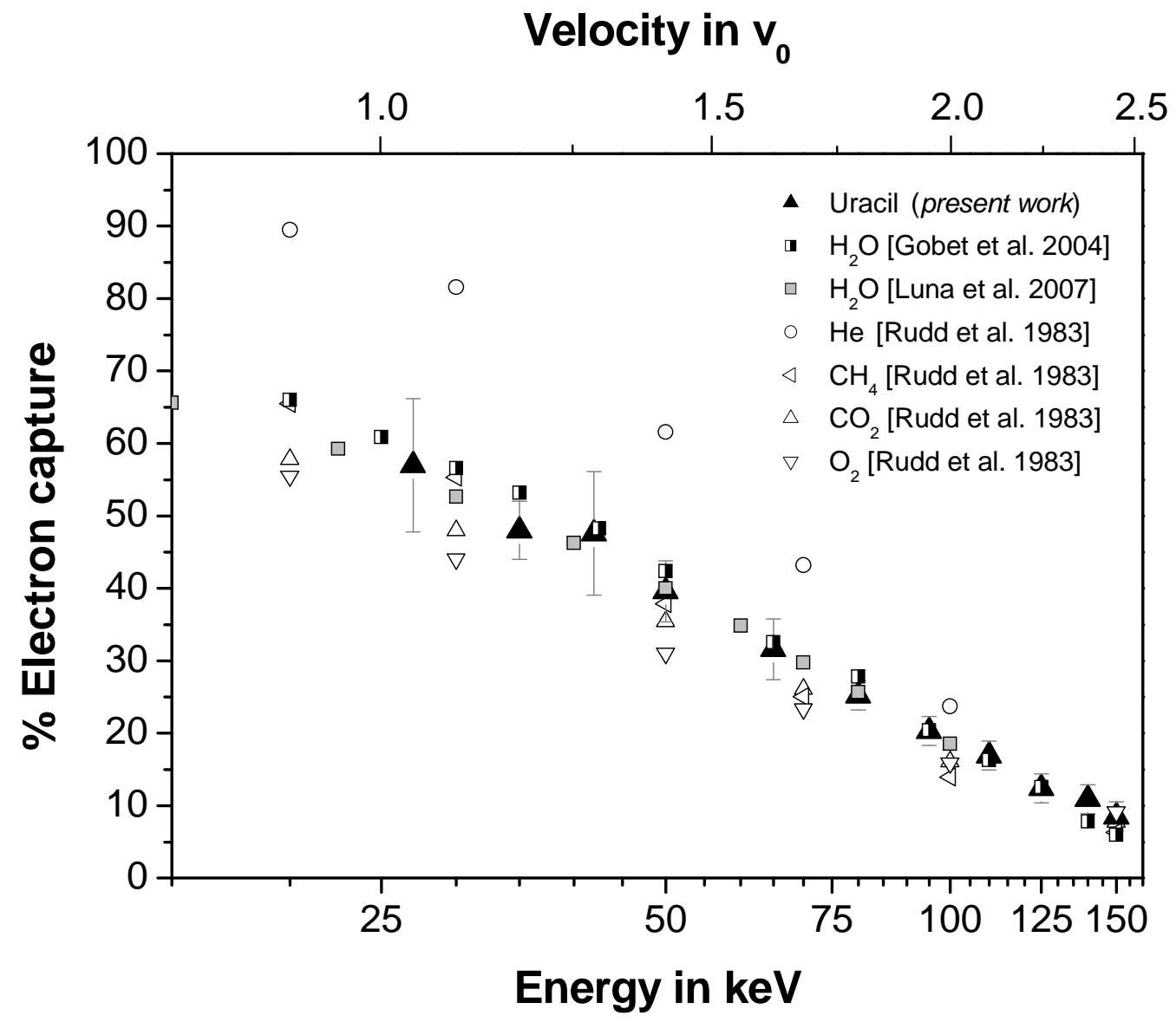


Table 1: Branching ratio between the two ionization modes, EC and DI, as expressed by the branching ratio $\mathrm{EC} / \mathrm{EC}+\mathrm{DI}$ and fragmentation branching ratios (fragment ion production / total ion production) for EC and DI at selected energies for 27-150 keV proton collisions with gas-phase nucleobase molecules.

\begin{tabular}{|c|c|c|c|c|c|c|c|}
\hline & \multicolumn{7}{|c|}{ Branching ratio (\%) * } \\
\hline & \multicolumn{4}{|c|}{ Uracil } & \multirow{2}{*}{$\begin{array}{l}(\%)^{*} \\
\text { Cytosine } \\
80 \mathrm{keV}\end{array}$} & \multirow{2}{*}{$\begin{array}{l}\text { Adenine } \\
80 \mathrm{keV}\end{array}$} & \multirow{2}{*}{$\begin{array}{l}\text { Thymine } \\
80 \mathrm{keV}\end{array}$} \\
\hline & $27 \mathrm{keV}$ & $42 \mathrm{keV}$ & $80 \mathrm{keV}$ & $150 \mathrm{keV}$ & & & \\
\hline$\frac{\text { Electron capture }(E C)}{\text { total ionization }(E C+D I)}$ & $\begin{array}{l}57.0 \\
\pm 9.2\end{array}$ & $\begin{array}{l}47.6 \\
\pm 8.5\end{array}$ & $\begin{array}{l}25.4 \\
\pm 2.0\end{array}$ & $\begin{array}{l}8.5 \\
\pm 2.0\end{array}$ & $\begin{array}{l}27.6 \\
\pm 4.0\end{array}$ & $\begin{array}{l}27.1 \\
\pm 4.0\end{array}$ & $\begin{array}{l}26.6 \\
\pm 4.0\end{array}$ \\
\hline$\frac{\text { Fragment ion production by EC }}{\text { Total EC (fragment + parent ions) }}$ & $\begin{array}{l}89.8 \\
\pm 0.7\end{array}$ & $\begin{array}{l}90.5 \\
\pm 0.7\end{array}$ & $\begin{array}{l}90.4 \\
\pm 0.7\end{array}$ & $\begin{array}{l}88.6 \\
\pm 1.8\end{array}$ & $\begin{array}{l}91.9 \\
\pm 0.5\end{array}$ & $\begin{array}{l}91.6 \\
\pm 1.0\end{array}$ & $\begin{array}{l}94.1 \\
\pm 0.4\end{array}$ \\
\hline$\frac{\text { Fragment ion production by DI }}{\text { Total DI (fragment + parent ions) }}$ & $\begin{array}{l}94.5 \\
\pm 2.7\end{array}$ & $\begin{array}{l}84.0 \\
\pm 3.6\end{array}$ & $\begin{array}{l}84.5 \\
\pm 0.7\end{array}$ & $\begin{array}{l}84.7 \\
\pm 0.8\end{array}$ & $\begin{array}{l}84.9 \\
\pm 0.6\end{array}$ & $\begin{array}{l}82.8 \\
\pm 1.6\end{array}$ & $\begin{array}{l}89.3 \\
\pm 0.8\end{array}$ \\
\hline
\end{tabular}

* The errors are generally greater for the branching ratios involving DI detection at $42 \mathrm{keV}$ because the channeltron signal threshold had to be set quite close to the noise level. 
Table 2: Absolute cross sections of electron capture, direct ionization, and total ionization in $80 \mathrm{keV}$ proton collisions with gas-phase cytosine, uracil, thymine, and adenine.

\begin{tabular}{|c|c|c|c|}
\hline \multirow{2}{*}{ Nucleobase } & \multicolumn{3}{|c|}{ Cross section $\left(\mathbf{1 0}^{-15} \mathbf{c m}^{\mathbf{2}}\right)$} \\
\cline { 2 - 4 } & Electron capture & Direct ionization & Total ionization \\
\hline Cytosine $(111 \mathrm{amu})$ & $2.3 \pm 0.5$ & $6.0 \pm 1.2$ & $8.3 \pm 1.6$ \\
\hline Uracil $(112 \mathrm{amu})$ & $6.0 \pm 1.2$ & $17.7 \pm 3.5$ & $23.8 \pm 4.8$ \\
\hline Thymine $(126 \mathrm{amu})$ & $6.3 \pm 1.3$ & $17.3 \pm 3.5$ & $23.6 \pm 4.7$ \\
\hline Adenine $(135 \mathrm{amu})$ & $5.8 \pm 1.2$ & $15.5 \pm 3.1$ & $21.2 \pm 4.2$ \\
\hline
\end{tabular}

